ElBakri et al., Afr., J. Infect. Dis. (2018) 12 (2): 7-13

https://doi.org/10.21010/ajid.v12i2.2

\title{
PREVALENCE OF CRYPTOSPORIDIUM SPP. AMONG ASYMPTOMATIC HEALTHY EXPATRIATE WORKERS IN SHARJAH, UNITED ARAB EMIRATES
}

\author{
Ali ElBakri ${ }^{1}$, Lazarus Mogane ${ }^{2}$, Sinda Ezzedine ${ }^{1}$, Natasha Potgieter $^{2}$, Pascal Bessong ${ }^{3}$, \\ Raed AbuOdeh ${ }^{1, *}$, Amidou Samie ${ }^{2}$
}

${ }^{1}$ Medical Laboratory Sciences Department, College of Health Sciences, University of Sharjah, Sharjah, United Arab Emirates; ${ }^{2}$ University of Venda, Department of Microbiology, Thohoyandou, South Africa; ${ }^{3}$ HIV/AIDS and Global Health Research Programme, Department of Microbiology, University of Venda, Thohoyandou, South Africa.

*Corresponding Author Email: raedabuodeh62@gmail.com

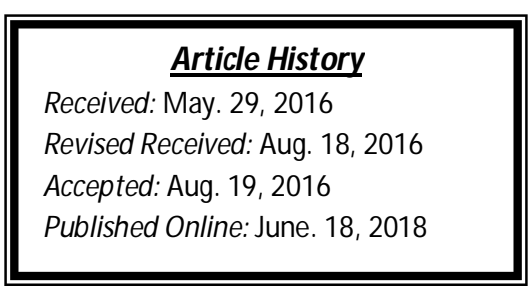

\begin{abstract}
Background: Epidemiological data on Cryptosporidium infections in the United Arab Emirates (UAE) is scarce. Therefore, the main objective of this study was to determine the prevalence of Cryptosporidium species among a community of expatriates in Sharjah, UAE working in different sectors, including the food industry, house maids and other domestic occupations.

Materials and Methods: One hundred and thirty four stool samples were collected from asymptomatic individuals presenting to the Sharjah Municipality Public Health Clinic (SMPHC) for screening of intestinal parasites for work permission purposes between 2009 and 2011. Demographic information such as age, sex, and country of origin was collected. Genomic DNA extracted from the stool samples were tested for Cryptosporidium species using real-time PCR (qPCR).

Results: Twenty-six individuals (19.4\%) were positive for Cryptosporidium sp. by PCR. The infection rate was found to be highest in Afghan nationals (33\%; 3/9) compared with the rest of the study population; yet, no significant association existed between nationality and infection rate. Moreover, no association was observed between infection rate and gender $\left(\chi^{2}=2.439 ; \mathrm{P}=0.118\right)$, nor infection rate and age group $\left(\chi^{2}=1.219 ; \mathrm{P}=0.544\right)$.

Conclusion: Infection by Cryptosporidium sp. was common in the study group, and further studies are needed within the native Emirati population before any conclusions can be made about foreigners potentially transmitting the parasite. Furthermore, data provided in this study could help determine its public and veterinary significance particularly in outbreaks in the country.
\end{abstract}

Keywords: Cryptosporidium; prevalence; PCR; Sharjah; United Arab Emirates

\section{Introduction}

Cryptosporidium species infections remain a major concern in waterborne disease outbreaks in many countries (Feltus et al, 2006; Fayer, 2004). Direct fecal oral route or consumption of food or water contaminated with infective oocysts is the main mode of transmission (Caccio, 2004). While different in their geographic distribution, both the anthroponotic (C. hominis and C. parvum) and zoonotic (C. parvum) species present a unique public health challenge to humans (Feltus et al, 2006; Sunnotel et al, 2006). Numerous diarrheal outbreaks of cryptosporidiosis have been reported from countries such as the United States and Sweden as well as in other developed and developing countries (MacKenzie et al, 1994; Insulander et al, 2005; Samie et al, 2006).

The prevalence of Cryptosporidium varies widely between countries and regions (Samie et al, 2015). Furthermore, epidemiological data on the prevalence of Cryptosporidium infections appear limited in most North African and Middle Eastern countries, including the UAE. To the authors' knowledge, three studies included data on Cryptosporidium in the UAE (Trad et al, 2003; Zylan et al, 2008; Aljanahi and Khan, 2014).

In the UAE, expatriates form the driving workforce. They mainly come from countries with poor socioeconomic structure and often live in crowded conditions with poor sanitation. Thus, they may act as a source of Cryptosporidium transmission to other expatriates or the local Emirati population; especially if they work around recreational swimming pools, in the food industry, or in households (Dawson, 2005; Quiroz et al, 2000). To our 
knowledge, the prevalence of Cryptosporidium infections in the UAE and mainly in Sharjah is unknown. The present study aimed to provide preliminary data on the prevalence of Cryptosporidium infections in humans that could possibly help determine its public and veterinary significance. Therefore, the primary objective of this research was to determine the infection rate of Cryptosporidium species among the expatriate population living and working in the UAE using real time PCR (qPCR).

\section{Materials and Methods Study samples and demographic characteristics of the study population}

The study samples were part of previous research studies in the area (ElBakri et al, 2013; 2014). Briefly, the study group $(N=134)$ included expatriates from various nationalities. All were undergoing intestinal parasites stool screening as a mandatory pre-employment requirement at the Sharjah Municipality Public Health Clinic (SMPHC), UAE. Demographic information such as age, sex, and country of origin was kindly provided by the SMPHC.

\section{DNA extraction and real-time PCR (qPCR) detection of Cryptosporidium species}

Genomic DNA was extracted from the stool samples using the QIAamp stool DNA Mini Kit (Qiagen GmbH, Hilden, Germany) as per the manufacturer's recommendations. The PCR protocol based on the amplification of a specific sequence of the 18S rRNA gene was used to detect and quantify Cryptosporidium spp. (Samie et al, 2006; Parr et al, 2007). The primers used were: Crypt PF: 5'-CTG CGA ATG GCT CAT TAT AAC A-3' and Crypt PR: 5'- AGG CCA ATA CCC TAC CGT CT-3'. These primers were designed to detect the 18S rRNA gene of as many Cryptosporidium species as possible, with sequences matching C. hominis (AF093491), C. parvum (AF164102), C. meleagridis (AF112574), C. canis (AB210854), and C. suis (AF108861) completely and with a single base pair (bp) mismatch at forward primer position 5 of 22 for $C$. felis (AF112575) and position 18 of 22 for C. muris (X64343). Reactions were processed in total volumes of $20 \mu \mathrm{L}$, including $10 \mu \mathrm{L}$ of the $\mathrm{iQ}^{\mathrm{TM}} \mathrm{SYBR} \circledast$ Green Supermix (Bio-Rad, $\mathrm{CA}), 0.5 \mu \mathrm{L}$ of each primer $(20 \mu \mathrm{M}), 4 \mu \mathrm{L}$ of Nuclease Free (DNase, RNase, and Proteinase) water (Fisher Biotech, $\mathrm{NJ}$ ), and $5 \mu \mathrm{L}$ of genomic DNA extract. The cycling conditions were four cycles with cycle 1 for $13.5 \mathrm{~min}$ at $95^{\circ} \mathrm{C}$, cycle 2 was repeated 50 times with $45 \mathrm{~s}$ denaturation at $95^{\circ} \mathrm{C}, 45 \mathrm{~s}$ annealing at $60^{\circ} \mathrm{C}$ and $60 \mathrm{~s}$ chain extension at $72^{\circ} \mathrm{C}$ with data collection enabled during the last two steps. Cycle 3 was $72^{\circ} \mathrm{C}$ for $10 \mathrm{~s}$ with set point temperature increase after cycle 2 . The last cycle was held at $4^{\circ} \mathrm{C}$. Each run included at least two positive controls (Genomic DNA extracted from pure Cryptosporidium oocysts) and one negative control (water).

\section{Statistical Analysis}

Data were statistically analyzed using SPSS software statistic programme version 21 (Chi-square test).

\section{Results}

Out of the 134 stool samples examined, 26 (19.4\%) tested positive for Cryptosporidium. Figure 1 shows the amplification curve for the tested samples. Analysis of the age distribution of the screened individuals showed that 41 $(30.6 \%)$ were 25 years or less; $73(54.5 \%)$ were between 26-45 years, and 19 (14.2\%) were above 45 years. Of the 134 study subjects, $103(76.8 \%)$ were males and 31 (23.1\%) females. Table 1 displays the distribution of Cryptosporidiumpositive samples according to nationality. Although the infection rate was highest in Afghan nationals (33.3\%) compared to the rest of the study population, no significant association was found between nationality and infection rate.

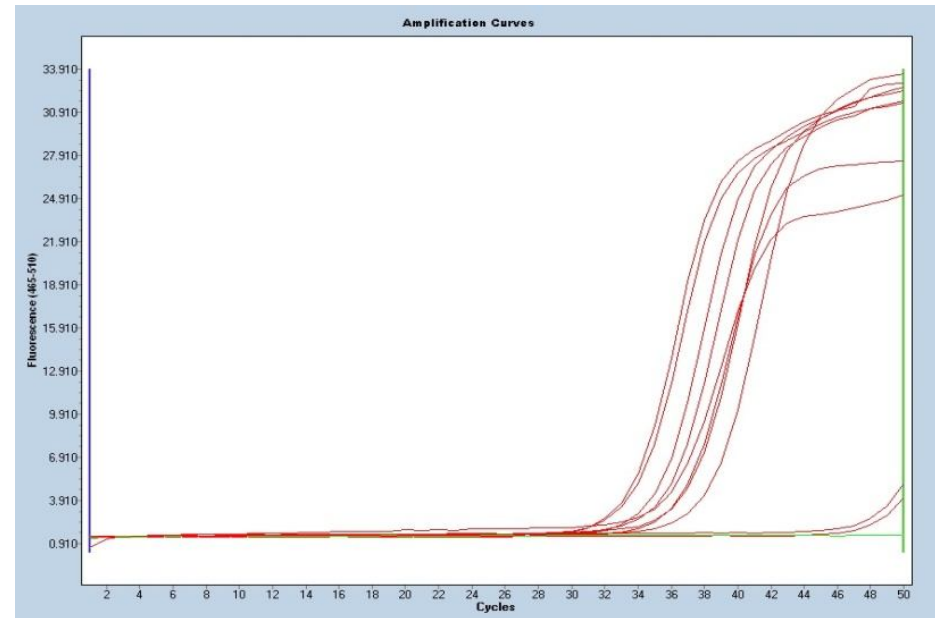

Figure 1. Amplification curves for Cryptosporidium spp. in isolates from Sharjah, UAE. 
Table 1 Rate of infection with Cryptosporidium according to nationality

Country of originNo. of Cryptosporidium-positive expatsTotal no. of expats examined

\begin{tabular}{|c|c|c|}
\hline Afghanistan & $3(33.3 \%)$ & 9 \\
\hline Bangladesh & $6(24 \%)$ & 25 \\
\hline Egypt & $1(25 \%)$ & 4 \\
\hline Ethiopia & $1(16.7 \%)$ & 6 \\
\hline India & $11(20.4 \%)$ & 54 \\
\hline Indonesia & 0 & 3 \\
\hline Iraq & 0 & 1 \\
\hline Jordan & 0 & 1 \\
\hline Nepal & 0 & 4 \\
\hline Pakistan & $2(14.3 \%)$ & 14 \\
\hline Philippines & $2(25 \%)$ & 8 \\
\hline Sri Lanka & 0 & 3 \\
\hline Sudan & 0 & 1 \\
\hline Tanzania & 0 & 1 \\
\hline
\end{tabular}

Table 2 illustrates the infection rate with Cryptosporidium according to gender and age group. No association was observed between infection rate and gender $\left(\chi^{2}=2.439 ; P=0.118\right)$ nor infection rate and age group $\left(\chi^{2}=1.219 ; P\right.$ $=0.544)$. Thus, among the analyzed variables none was statistically significant.

Single infection was observed in $30.7 \%$ (8/26) Cryptosporidium positive samples.

Co-infections were also identified and upon revising earlier published data on these previously analysed samples for Entamoeba complex and Giardia lamblia (ElBakri et al, 2013; 2014), co-infections with other intestinal protozoa were also observed (Table 3).

Table 2 Prevalence of Cryptosporidium with respect to socio-demographic characteristics of the study population

\begin{tabular}{lllll}
\hline Characteristics & No. examined & Positive No(\%) & $\chi^{2}$ & p-value \\
\hline $\begin{array}{l}\text { Gender } \\
\text { Male }\end{array}$ & 103 & $23(22.3 \%)$ & 2.439 & 0.118 \\
Female & 31 & $3(9.7 \%)$ & & \\
& & & & \\
Age group & & $10(24.4 \%)$ & 1.219 & 0.544 \\
25 years or less & 41 & $12(16.4 \%)$ & & \\
26-45 years & 73 & $3(15.8 \%)$ & & \\
$>45$ years & 19 & & & \\
\hline
\end{tabular}


Table 3 The frequency of Cryptosporidium appearing in mono- and co-infections.

\begin{tabular}{|c|c|c|c|}
\hline Type of infection & No & Total No & $\%$ \\
\hline Single infection & & 8 & 30.7 \\
\hline Double infection & & 12 & 46.2 \\
\hline Cryptosporidium + E. moshkovskii $*$ & 1 & & \\
\hline Cryptosporidium + G. lamblia & 9 & & \\
\hline Cryptosporidium + E. histolytica** & 2 & & \\
\hline Triple infection & & 4 & 15.4 \\
\hline Cryptosporidium + E. histolytica + G. lamblia & 3 & & \\
\hline Cryptosporidium + E. moshkovskii + G. lamblia & 1 & & \\
\hline Quadruple infection & & 2 & 7.7 \\
\hline Cryptosporidium $+E$. histolytica $+G$. lamblia $+E$. dispar*** & 1 & & \\
\hline Cryptosporidium + E. moshkovskii + G. lamblia + E. dispar & 1 & & \\
\hline Total no. of Cryptosporidium-infected cases & & 26 & 19.4 \\
\hline Total no. of samples & & 134 & \\
\hline
\end{tabular}

Note: $* * *, * * *$ The specific species of Entamoeba in the table was obtained from data published earlier by the author (ElBakri et al. 2013; 2014).

\section{Discussion}

The prevalence and species distribution of Cryptosporidium vary greatly from one region to another ranging from $0.99 \%$ to $60.6 \%$ (Chacin-Bonilla et al, 1993; Park et al, 2006; Horman et al, 2004; Wongstitwilairoong et al, 2007). In an epidemiological review of cryptosporidiosis in Saudi Arabia and regional countries between 1986 and 2006, Areeshi and colleagues reported a prevalence of Cryptosporidium infection in humans ranging from $1 \%$ to $37 \%$ with a median of $4 \%$, while in animals it was different for different species of animals and geographic locations of the studies (Areeshi et al, 2007). The prevalence of Cryptosporidium species infections in asymptomatic children in two neighboring countries - Saudi Arabia and India - were reported as 4.7\% and 2.3\%; respectively (Al-Braiken et al, 2003; Palit et al, 2005).

In the present work, we have shown, for the first time, that the prevalence of Cryptosporidium species in Sharjah, UAE is $19.4 \%$ (Table 1). The study population included expatriates applying for work permits to work in various sectors in the food industry and food handling, domestic helpers, drivers and in recreational facilities. While no association was noted between the rate of infection and the country of origin nor the age group $(P=0.544)$ of the participants, results showed that Cryptosporidium was more prevalent in Afghan nationals (33.3\%) with the majority $(24.4 \%)$ of those infected in the 25 years old or less age group. Furthermore, no significant difference existed between males and females $(\mathrm{p}=0.118)$ (Table 2). Comparable to results obtained in our study, a Venezuelan investigation reported a Cryptosporidium prevalence of $11.8 \%$ among food handlers in the Zulia State (Freites et al., 2009). Similarly, a South African study reported an $18 \%$ infection rate with Cryptosporidium using PCR with no significant difference between hospital samples (18\%) and school children samples (17\%) (Samie et al, 2006). However, unlike the present findings, in the same South African report the age groups most affected were from 2-5 years old (28.6\%) and 50-59 years old (50\%). The group affected in the present study (while not significant) was the 25 years old or less age group $(24.4 \%)$. This could be attributed to the composition of our test participants since most of the samples were from individuals in the 20-45 years age band. Therefore, in the present report, gender, age, and country of origin were not important variables and were not correlated with the presence of Cryptosporidium spp. (Samie et al, 2006; Park et al, 2006; Chai et al, 2001). Analyses of more samples may reveal an exact picture of the most affected age group and gender.

Contrary to results obtained in the present work, a study in Khartoum, Sudan reported no cryptosporidial infection in the stools of asymptomatic individuals working in the food business (Adam et al, 1994). Moreover, Körkoca et al. (2013) reported a (1.27\%) prevalence of Cryptosporidium spp. in asymptomatic food workers in Turkey. In Sari, Northern Iran, Sharif et al. (2015) reported a 3.1\% Cryptosporidium spp. prevalence among food handlers attending the public health center laboratory for annual check-up. Zaglool et al. (2011) reported a 2.5\% infection rate with Cryptosporidium spp. among food handlers in Makkah, Saudi Arabia. 
It is important to note that the wide discrepancy noted in the prevalence frequencies reported in the previous studies could be a result geographical, age of the study populations and seasonality (Schlundt et al, 2004; Laupland et al, 2005; Hlavsa et al, 2005).

Another equally important reason for the wide variation in rates of infection noted could be attributed to the different identification methodologies employed in the various reports (Fayer and Xiao, 2008; Sakarya et al, 2012).

Further, eighteen samples $(69.2 \%)$ were found to be co-infected with other intestinal protozoa. G. lamblia was found in 15/26 (57.7\%) samples whereas Entamoeba complex in 11/26 (42.3\%) samples (Table 3). Of the Entamoeba complex, E. histolytica was seen in 6/26 (23\%) samples, E. moshkovskii in 3/26 (11.5\%) samples and E. dispar in 2/26 $(7.7 \%)$ samples (ElBakri et al, 2013; 2014). Co-infections with other parasites such as G. lamblia and E. histolyticaldispar were reported in other studies (Braiken et al, 2003). Because of the poor quality and deterioration of the DNA samples (following multiple freeze-thaw cycles for 5-6 years), a major limitation of the study was the inability to confirm those positive isolates by conventional SSU rDNA and sequencing in order to ascertain the species in the study population.

Limited data is available regarding Cryptosporidium species in circulation in the UAE. The first report on the coccidian parasite was in 2003 by Trad and colleagues on the eradication of Cryptosporidium in four children with acute lymphoblastic leukemia (Trad et al, 2003). Another study reported on cryptosporidiosis in a collection of stonecurlews in Dubai (Zylan et al, 2008). Furthermore, a recent study in Dubai reported the presence of Cryptosporidium and Giardia in swimming pool water in two schools (Aljanahi and Khan, 2014). Expatriates form the driving workforce in the UAE. They mainly come from less developed countries and often live under crowded conditions with poor sanitation. As a result, they may act as a source of Cryptosporidium transmission to other expatriates or the local Emirati population; especially if they work around recreational swimming pools, in the food industry, or in households. Food handlers and others employed in the food industry play a significant role as a source of contamination to the various food products (Millar et al, 2002; Ponka et al, 2009). Furthermore, thick walled oocysts can survive for many months in ideal environmental conditions. Thus, asymptomatic carriage of Cryptosporidium spp. can cause person-toperson transmission.

We have shown previously that E. histolytica as well as Giardia lamblia infections are seen among the same study group (ElBakri et al, 2013; 2014). They mainly originate from the Indian subcontinent, Southeast Asia and Africa where poor socio-economic levels, poor sanitation and inadequate medical care are common. The possible spread of Cryptosporidium spp. right through the native Emirati local community and other groups of migrants also needs to be considered, in the context of these working groups since they often are employed to care for young children and elderly who are more prone to Cryptosporidium infections. On the other hand, there is an urgent need for further studies within the native Emirati population before any conclusion can be made about foreigners transmitting Cryptosporidium spp. to the local community as it is also probable that the local inhabitants may in fact infect the foreigners. Moreover, this study will also bring into focus this potentially public health problem to the local authorities and could possibly help determine its public and veterinary significance particularly in outbreaks.

The present findings indicate that asymptomatic expatriate individuals working in the food sector and in other various jobs can be source of cryptosporidiosis outbreak. Thus, identifying those with asymptomatic cryptosporidiosis and taking the necessary actions in case of its determination are important in respect of public health.

Conflict of interest: All authors declare that they or their institutions have no financial and personal relationship with other people or organizations that could inappropriately influence their work.

\section{Acknowledgements}

We sincerely thank Dr. Mousa AlAzzawi from the Sharjah Municipality Public Health Clinic and the laboratory staff for their incessant support and for providing us with the data and samples for the purpose of this research project.

\section{References}

1. Adam, A.A., Hassan, H.S., Shears, P. and Elshibly, E. (1994). Cryptosporidium in Khartoum, Sudan. East Afr. Med. J. 71: 745-746.

2. Al-Braiken, F.A., Amin, A., Beeching, N.J., Hommel, M. and Hart, C.A. (2003). Detection of Cryptosporidium amongst diarrhoeic and asymptomatic children in Jeddah, Saudi Arabia. Ann. Trop. Med. Parasitol. 97: 505-510.

3. Aljanahi, A.A.A. and Khan, M.A. (2014). A preliminary assessment of the occurrence of Cryptosporidium and Giardia in the school swimming pool water in Dubai, United Arab Emirates. Inter. J. Environ. Sci. Develop. 5: 303-308.

4. Areeshi, M.Y., Beeching, N.J. and Hart, C.A. (2007). Cryptosporidiosis in Saudi Arabia and neighbouring countries. Ann. Saudi Med. 27: 325-332.

5. Caccio, S.M. (2004). New methods for the diagnosis of Cryptosporidium and Giardia. Parassitologia 46: 151155. 
6. Chai, J.Y., Kim, N.Y., Guk, S.M., Park, Y.K., Seo, M., Han, E.T. and Lee, S.H. (2001). High prevalence and seasonality of cryptosporidiosis in a small rural village occupied predominantly by aged people in the Republic of Korea. Am. J. Trop. Med. Hyg. 65: 518-522.

7. Chacin-Bonilla, L., Mejia De Young, M., Cano, G., Guanipa, N., Estevez, J. and Bonilla, E. (1993). Cryptosporidium infections in a suburban community in Maracaibo, Venezuela. Am. J. Trop. Med. Hyg. 49: 63-67.

8. Dawson, D. (2005). Foodborne protozoan parasites. Int. J. Food Microbiol. 103: 207-227.

9. ElBakri, A., Samie, A., Ezzedine, S. and AbuOdeh, R. (2013). Differential detection of Entamoeba histolytica, Entamoeba dispar and Entamoeba moshkovskii in fecal samples by nested PCR in the United Arab Emirates. Acta Parasitol. 58: 185-190.

10. ElBakri, A., Samie, A., Bessong, P., Potgieter, N. and Odeh, R.A. (2014). Detection and molecular characterisation of Giardia lamblia genotypes in Sharjah, United Arab Emirates. Trans. R. Soc. Trop. Med. Hyg. 108: 466-473.

11. Fayer, R. (2004). Cryptosporidium: a water-borne zoonotic parasite. Vet. Parasitol. 126: 37-56.

12. Fayer, R. and Xiao, L. (2008). Cryptosporidium and Cryptosporidiosis. $2^{\text {nd }}$ Ed. Boca Raton: CRC Press Taylor \& Francis Group.

13. Feltus, D.C., Giddings, C.W., Schneck, B.L., Monson, T., Warshauer, D. and McEvoy, J.M. (2006). Evidence supporting zoonotic transmission of Cryptosporidium spp. in Wisconsin. J. Clin. Microbiol. 44: 4303-4308.

14. Freites, A., Colmenares, D., Pérez, M., García, M. and Díaz de Suárez, O. (2009). Cryptosporidium sp infections and other intestinal parasites in food handlers from Zulia State, Venezuela. Invest. Clín. 50: 13-21.

15. Hlavsa, M.C., Watson, J.C. and Beach, M.J. (2005). Cryptosporidiosis surveillance United States 1999-2002. MMWR. 54: 1-8.

16. Horman, A., Korpela, H., Sutinen, J., Wedel, H. and Hanninen, M-L. (2004). Metaanalysis in assessment of the prevalence and annual incidence of Giardia spp. and Cryptosporidium spp. infections in humans in the Nordic countries. Int. J. Parasitol. 34: 1337-1346.

17. Insulander, M., Lebbad, M., Stenstrom, T.A. and Svenungsson, B. (2005). An outbreak of cryptosporidiosis associated with swimming pool water. Scan. J. Infect. Dis. 37: 354-360.

18. Körkoca, H., Göz, Y., Ataş, A.D., Kurtoğlu, M.G., Ekici, K. and Berktaş, M. (2013). Prevalence of Cryptosporidium spp. in asymptomatic food workers. Turkiye Parazitol. Derg. 37: 241-244. doi: 10.5152/tpd.2013.2981.

19. Laupland, K.B. and Church, D.L. (2005). Population-based laboratory surveillance for Giardia sp. and Cryptosporidium spp. infections in a large Canadian health region. BMC Infect. Dis. 5: 72.

20. MacKenzie, W.R., Hoxie, N.J., Proctor, M.E., Gradus, M.S., Blair, K.A. and Peterson, D.E.A. (1994). Massive outbreak in Milwaukee of Cryptosporidium infection transmitted through the public water supply. New Eng. J. Med. 33: 161-167.

21. Millar, B.C., Finn, M., Xiao, L., Lowery, C.J., Dooley, J.S.G. and Moore, J.E. (2002). Cryptosporidium in foodstuffs-an emerging aetiological route of human foodborne illness. Trends Food Sci. Tech. 13: 168-187.

22. Palit, A., Sur, D., MitraDhar, K. and Saha, M.R. (2005). Asymptomatic cryptosporiosis in a periurban slum setting in Kolkata, India-a pilot study. Jpn. J. Infect. Dis. 58: 110-111.

23. Park, J.H., Kim, H.J., Guk, S.M., Shin, E.H., Kim, J.L., Rim, H.J., Lee, S.H. and Chai, J.Y. (2006). A survey of cryptosporidiosis among 2,541 residents of 25 coastal islands in Jeollanam-Do (Province), Republic of Korea. Korean J. Parasitol. 44: 367-372.

24. Parr, J.B., Sevilleja, J.E., Samie, A., Alcantara, C., Stroup, S.E., Kohli, A., Fayer, R., Lima, A.A., Houpt, E.R. and Guerrant, R.L. (2007). Detection and quantification of Cryptosporidium in HCT-8 cells and human fecal specimens using real-time polymerase chain reaction. Am. J. Trop. Med. Hyg. 76: 938-942.

25. Ponka, A., Kotilainen, H., Rimhanen-Finne, R., Hokkanen, P., Hanninen, M.L., Kaarna, A., Meri, T. and Kuusi, M. (2009). A foodborne outbreak due to Cryptosporidium parvum in Helsinki, November 2008. Euro. Surveill. 14: 19269.

26. Quiroz, E.S., Bern, C., MacArthur, J.R., Xiao, L., Fletcher, M., Arrowood, M.J., Shay, D.K., Levy, M.E., Glass, R.I. and Lal, A. (2000). An outbreak of cryptosporidiosis linked to a foodhandler. J. Infect. Dis. 181: 695-700.

27. Samie, A., Bessong, P.O., Obi, C.L., Sevilleja, J.E., Stroup, S., Houpt, E. and Guerrant, R.L. (2006). Cryptosporidium species: preliminary descriptions of the prevalence and genotype distribution among school children and hospital patients in the Venda region, Limpopo Province, South Africa. Exp. Parasitol. 114: 314322.

28. Samie, A., Al-Qahtani, A., El Bakri, A. and Ehdaie, B. (2015). Challenges and Innovative Strategies to Interrupt Cryptosporidium Transmission in Resource-Limited Settings. Curr. Trop. Med. Rep. 2: 161-170. DOI 10.1007/s40475-015-0057-8.

29. Sakarya, Y., Kar, S., Tanyuksel, M., Karaer, Z., Babur, C. and Vatansever, Z. (2012). Detection of Cryptosporidium spp. in humans and calves through nested PCR and carbol fuchsin staining methods in Ankara, Turkey. Kafkas Univ. Vet. Fak. Derg. 18: 531-536.

30. Schlundt, J., Toyofuku, H., Jansen, J. and Herbst, S.A. (2004). Emerging food-borne zoonoses. Rev. Sci. Tech. 23: 513-533. 
31. Sharif, M., Daryani, A., Kia, E., Rezaei, F., Nasiri, M. and Nasrolahei, M. (2015). Prevalence of intestinal parasites among food handlers of Sari, Northern Iran. Rev. Inst. Med. Trop. Sao Paulo. 57: 139-144. doi: 10.1590/S0036-46652015000200007.

32. Sunnotel, O., Lowery, C.J., Moore, J.E., Dooley, J.S.G., Xiao, L., Millar, B.C., Rooney, P.J. and Snelling, W.J. (2006). Cryptosporidium. Lett. Appl. Microbiol. 1: 7-16.

33. Trad, O., Jumaa, P., Uduman, S. and Nawaz, A. (2003). Eradication of Cryptosporidium in four children with acute lymphoblastic leukemia. J. Trop. Pediatr. 49: 128-130.

34. Wongstitwilairoong, B., Srijan, A., Serichantalergs, O., Fukuda, C.D., Mcdaniel, P., Bodhidatta, L. and Mason, C.J. (2007). Intestinal parasitic infections among pre-school children in Sangkhlaburi, Thailand. Am. J. Trop. Med. Hyg. 76: 345-350.

35. Zaglool, D.A., Khodari, Y.A., Othman, R.A.M. and Farooq, M.U. (2011). Prevalence of intestinal parasites and bacteria among food handlers in a tertiary care hospital. Niger. Med. J. 52: 266-270. doi: 10.4103/03001652.93802 .

36. Zylan, K., Bailey, T., Smith, H.V., Silvanose, C., Kinne, J., Schuster, R.K. and Hyland, K. (2008). An outbreak of cryptosporidiosis in a collection of Stone curlews (Burhinus oedicnemus) in Dubai. Avian Pathol. 37: 521-526. 